\title{
Enfermedad de injerto cutáneo contra huésped
}

Cutaneous graft versus host disease

\author{
Claudia Liliana Montoya' ${ }^{1}$, Melibea Sierra² ${ }^{2}$ Andrés Vidal $^{3}$ \\ 1. Médica dermatóloga, Fundación Valle de Lili, Cali, Colombia. \\ 2. Médica interna, Universidad Icesi-Fundación Valle de Lili, Cali, Colombia. \\ 3. Médico dermatólogo; jefe de posgrado en Dermatología, Universidad Icesi-Fundación Valle de Lili, Cali, Colombia.
}

\section{RESUMEN}

El trasplante de células hematopoyéticas es un tratamiento potencialmente curativo para enfermedades hematológicas neoplásicas o no neoplásicas, en el cual se administra quimioterapia condicionante, radioterapia o ambas, para tratar la enfermedad de base y ocasionar una supresión inmunitaria que prevenga el rechazo del injerto. Posteriormente, se hace una infusión en el receptor de células hematopoyéticas progenitoras derivadas de médula ósea, sangre periférica o sangre de cordón umbilical. La piel se afecta en el 81 \% de los pacientes, constituyéndose en el órgano más frecuentemente comprometido y ocasionando una heterogeneidad de lesiones clínicas a las cuales el dermatólogo debe enfrentarse; su diagnóstico y tratamiento son, en muchas ocasiones, un reto.

PALABRAS CLAVE: trasplante células hematopoyéticas, injerto contra huésped, manifestaciones cutáneas, tolerancia inmunitaria.

\section{SUMMARY}

Hematopoietic stem cell transplantation is a potentially curative therapy for hematologic neoplastic or non-neoplastic diseases, in which a conditioning chemotherapy and/or radiation therapy are given to treat the underlying disease and cause immune suppression to prevent graft rejection, and then infusing in the receptor, hematopoietic progenitor cells derived from bone marrow, peripheral blood or cord blood. The skin is affected in $81 \%$ of patients, becoming the organ most frequently compromised and causing heterogeneity of clinical lesions to which the dermatologist must face, being often a challenge to diagnosis and treatment.

KEYWORDS: Hematopoietic stem cell transplantation, cutaneous graft versus host disease, immune tolerance.

\section{INTRODUCCIÓN}

Actualmente se realizan 25.00o trasplantes de células hematopoyéticas al año en el mundo ${ }^{1}$ y la enfermedad de injerto contra huésped es la principal causa de muerte no relacionada con la recaída de la enfermedad primaria ${ }^{2}$. Ocurre cuando las células inmunitarias de un injerto de donante no idéntico, reconocen las diferencias con el receptor del trasplante, por lo cual se desarrolla una reacción inmunológica que causa enfermedad en el huésped. En otras palabras, es una manifestación exagerada de una reacción inflamatoria normal, en la cual los linfocitos T donados
Correspondencia:

Claudia Liliana Montoya

Email:

gabclau@outlook.com

Recibido: 24 de julio de 2015

Aceptado: 30 de enero de 2016

No se reportan conflictos de interés. 


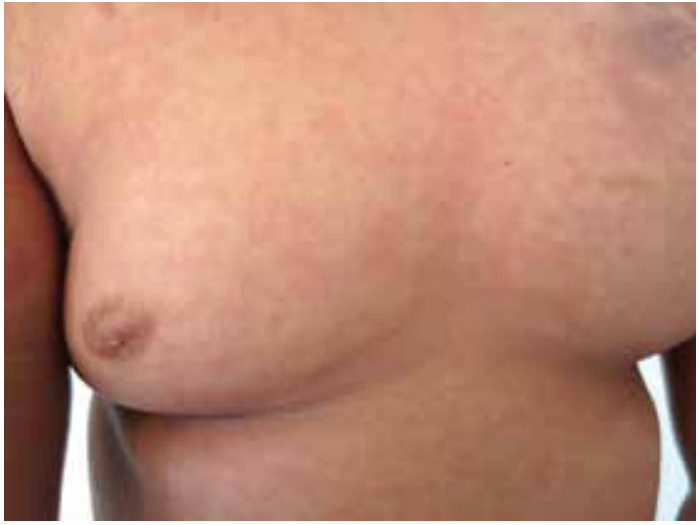

FIGURA 1. Enfermedad aguda de injerto contra huésped: erupción maculopapular, eritematosa y morbiliforme, en la cara anterior del tórax anterior y el abdomen.

encuentran diferencias antigénicas en un medio que fomenta la inflamación. El trasplante puede ser autólogo, células hematopoyéticas del mismo paciente, o alogénico, de un donante familiar o no familiar o uno no relacionado de los bancos de células de cordón umbilical. La reacción entre el injerto hematopoyético y el receptor da lugar a la enfermedad injerto contra huésped $\mathrm{y}$, también, al efecto terapéutico denominado injerto contra tumor ${ }^{3}$.

La piel se encuentra afectada en el $81 \%$ de los pacientes, constituyéndose en el órgano más frecuentemente comprometido, seguido por el tubo digestivo $(54 \%)$ y el hígado $(50 \%)^{4}$.

En 1966, Billingham estableció criterios para que exista una enfermedad injerto contra huésped, los cuales continúan vigentes ${ }^{5}$

- El trasplante hematopoyético debe contener células inmunocompetentes, viables y funcionales.

- Las células del injerto hematopoyético deben reconocer diferencias antigénicas entre el donante y el receptor.

- El huésped debe ser incapaz de montar una reacción inmunitaria efectiva que elimine las células trasplantadas, caso en el cual se daría el rechazo y la pérdida del injerto.

La enfermedad de injerto contra huésped clásicamente se ha clasificado en aguda, si las lesiones aparecen en los primeros 100 días después del trasplante, y en crónica, si aparecen después de 100 días. Sin embargo, debido a que sus manifestaciones no siempre cumplen estos criterios, en el 2004, los National Institutes of Health (NIH) establecieron una reclasificación ${ }^{6-9}$ :

\section{Enfermedad aguda de injerto contra huésped:}

- Clásica: en los primeros 100 días después del trasplante.

- Persistente: manifestaciones agudas que se mantienen más allá de los 100 días.

- Recurrente: recaída de un episodio agudo más alla de los primeros 100 días.

- De inicio tardío: manifestaciones agudas que comienzan después de los 100 días y se relacionan, especialmente, con la suspensión o disminución de los medicamentos inmunosupresores.

\section{Enfermedad crónica de injerto contra huésped:}

- Clásica: después de 100 días del trasplante.

- Síndrome de superposición, el cual tiene características diagnósticas o presuntivas de enfermedad crónica de injerto contra huésped y, además, las típicas de la forma aguda.

La enfermedad crónica de injerto contra huésped puede presentarse después de su forma aguda (progresiva), luego de un periodo libre de síntomas (quiescente) o sin la forma aguda previa (de novo $)^{10}$.

\section{ENFERMEDAD AGUDA DE INJERTO CONTRA HUÉSPED}

La incidencia varía entre 20 y $70 \%$, dependiendo del grado de disparidad del HLA, de la intensidad del esquema de acondicionamiento, de la edad del receptor y del estadio de la enfermedad primariaa,10,11. Los órganos más frecuentemente comprometidos son la piel, el hígado y el tubo digestivo.

El factor de riesgo más importante para la enfermedad aguda de injerto contra huésped es la disparidad en el HLA. Se ha encontrado que, entre hermanos con HLA idéntico que reciben un trasplante alogénico, la incidencia de la enfermedad aguda es mucho más baja, alrededor del $20 \%$, que entre aquellos que reciben varios injertos no relacionados ${ }^{12,13}$. La incidencia de enfermedad aguda de injerto contra huésped de grado III/IV es de $30 \%$ en donantes no relacionados con HLA idéntico, de $40 \%$ en aquellos con una disparidad en uno o dos alelos de la clase I, especialmente HLA-A, y de, aproximadamente, $33 \%$ cuando se trata de trasplantes de familiares pero con disparidad en uno o dos alelos ${ }^{14-16}$. 


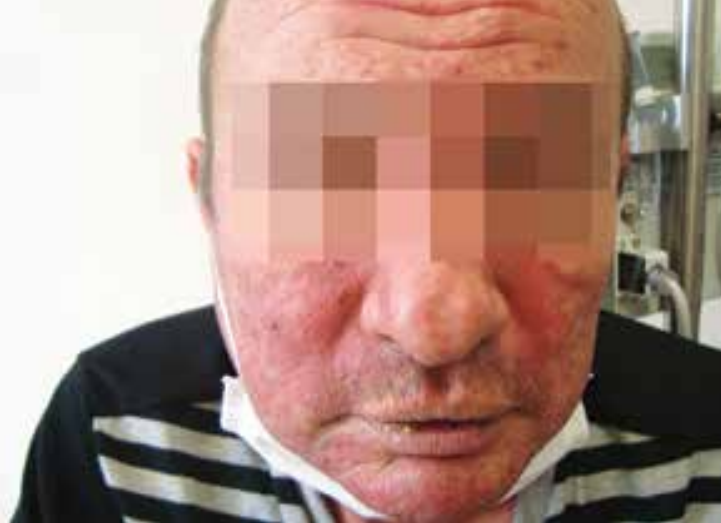

FIGURA 2. Enfermedad aguda de injerto contra huésped: placas eritematosas, descamativas y confluentes en la cara.

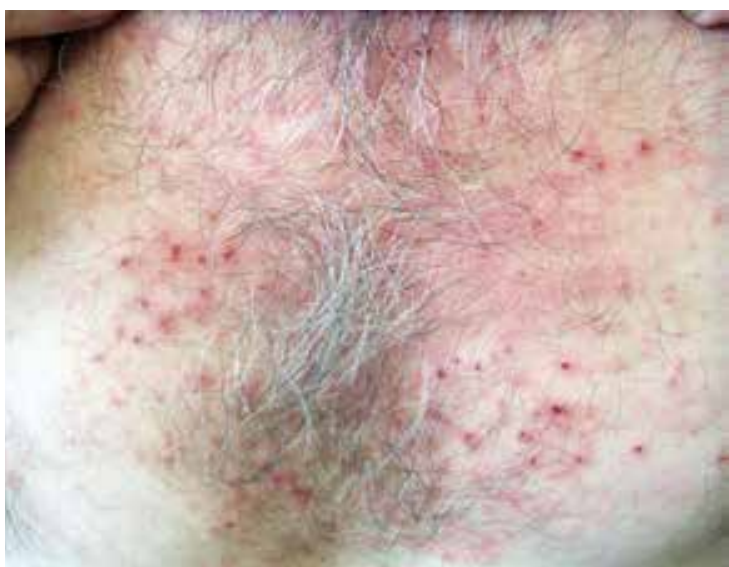

FIGURA 4. Enfermedad aguda de injerto contra huésped: pápulas foliculares eritematosas en el tórax.

Las manifestaciones cutáneas tempranas se inician, en promedio, en el día 19 después del trasplante (rango: 5 a 47 días) 3 . Consisten en una erupción máculo-papular de tipo morbiliforme, con descamación, que se inicia en la parte superior del tronco y el cuello, y se extiende a palmas, plantas, orejas, mejillas, flancos y cara interna de los muslos, y puede evolucionar a vesículas o eritrodermia, con compromiso de las palmas y plantas. Puede estar acompañada de prurito y dolor. El inicio del exantema usualmente se correlaciona con el momento en que las células del donante han completado su proceso de injertarse en el receptor (engrafment), caracterizado por la presencia de más de $5 \times 10^{8} / \mathrm{L}$ neutrófilos por tres días consecutivos ${ }^{15}$ (FIGURAS 1-5).

El compromiso sistémico se ha valorado cuantitativamente en grados de I a IV, con base en el tipo de compromiso cutáneo, el grado de elevación de las bilirrubinas

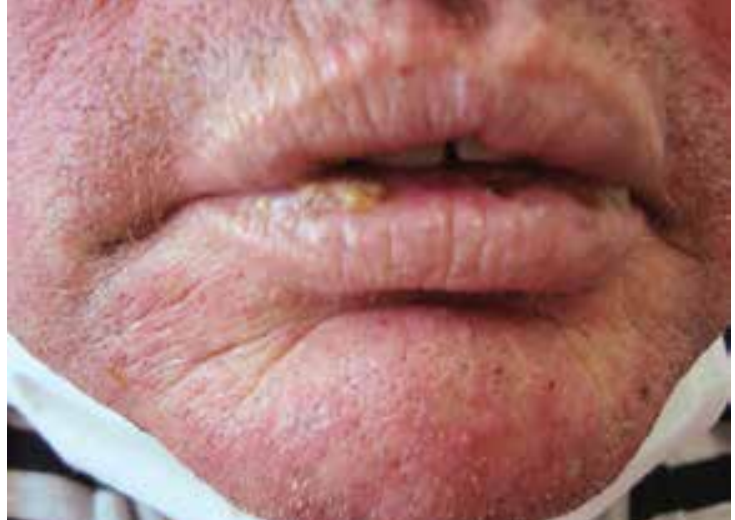

FIGURA 3. Enfermedad aguda de injerto contra huésped: compromiso de la mucosa oral.

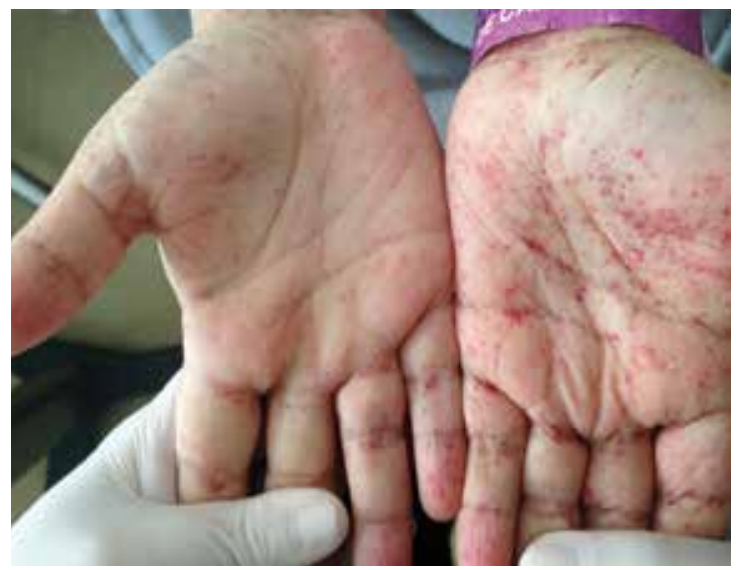

FIGURA 5. Enfermedad aguda de injerto contra huésped: eritema y pápulas purpúricas en las palmas.

y el volumen de las deposiciones diarreicas ${ }^{17}$ (TABLA 1).

La enfermedad aguda de injerto contra huésped de presentación precoz, a menudo tiene un curso clínico agresivo y grave ${ }^{21}$, así como el grado IV de compromiso cutáneo, con una mortalidad de hasta el $80 \%$.

Los cambios histopatológicos consisten en apoptosis de la capa basal o de la capa espinosa inferior, el infundíbulo, la vaina radicular externa, el promontorio del folículo piloso o en el acrosiringio, que puede asociarse o no a una dermatitis de interfase con cambios vacuolares predominantemente en la capa basal, con o sin satelitosis de linfocitos. Estos hallazgos pueden confirmar el diagnóstico, pero no diferencian el grado de la enfermedad; además, no son patognomónicos y puede ser difícil diferenciarlos de las reacciones medicamentosas $^{3,18}$ (TABLA 2).

El compromiso de la mucosa oral se observa hasta 


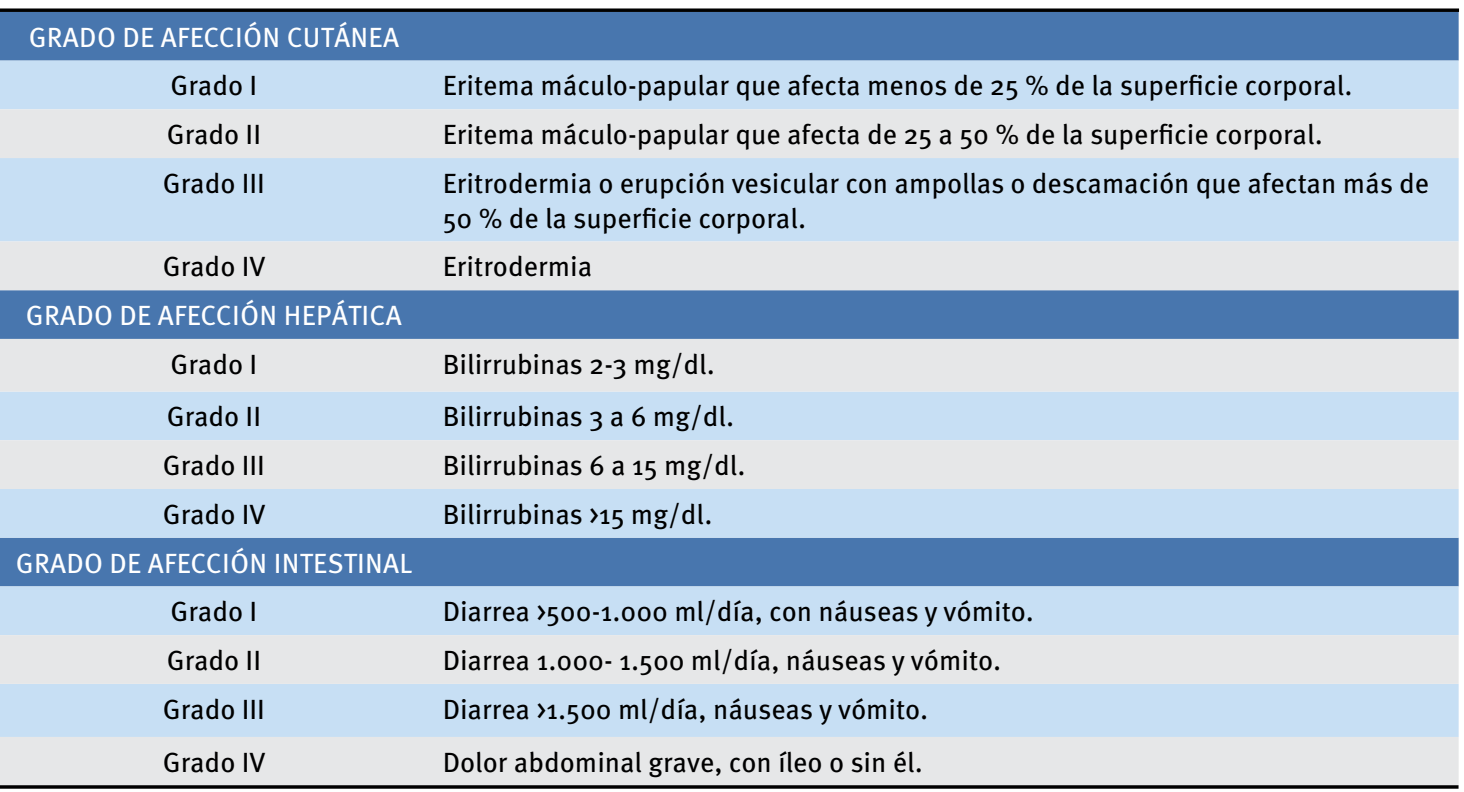

TABLA 1. Grado de compromiso sistémico.

\begin{tabular}{cl}
\hline Grado o & Piel normal. \\
Grado I & Degeneración vacuolar de queratinocitos basales. \\
Grado II & Células disqueratósicas y apoptósicas en la epidermis. \\
Grado III & Degeneración vacuolar intensa con formación de fisuras epidermo-dérmicas. \\
Grado IV & Ampolla subepidérmica con necrosis epidérmica. \\
\hline
\end{tabular}

TABLA 2. Alteraciones dermatopatológicas en enfermedad aguda injerto contra huésped. en $80 \%$ de los pacientes y se manifiesta por mucositis, xerostomía, úlceras o infecciones. Las úlceras usualmente ocurren dos semanas después de la quimioterapia y se resuelven aproximadamente en dos a cuatro semanas después de su suspensión ${ }^{19}$. Algunos autores mencionan que las lesiones que persistan por más de tres semanas después del trasplante o aquellas que involucren el paladar duro, inclinan más el diagnóstico hacia una enfermedad aguda de injerto contra huésped que a mucositis secundaria a quimioterapia $^{20}$. Es importante mencionar que, en ocasiones, este cuadro clínico no se documenta adecuadamente, ya que es difícil diferenciarlo de una mucositis secundaria a quimioterapia y, aunque la biopsia tiene riesgo de infección, dolor y sangrado, es importante obtenerla para confirmar el diagnóstico ${ }^{20}$.

Se han establecido protocolos para la prevención y el tratamiento de este tipo de lesiones, como el de Levy-Polack ${ }^{21}$. Se deben iniciar tres semanas antes de iniciar la quimioterapia y con ellos se debe eliminar la placa bacteriana con enjuagues con clorhexidina al 0,12 \%, aplicación tópica de yodo-povidona y enjuagues con una solución de $500.000 \mathrm{U}$ de nistatina ${ }^{22}$. La xerostomía debe tratarse con saliva artificial, lubricantes y humidificadores de la mucosa oral. La mucositis y las úlceras bucales pueden manejarse con anestésicos tópicos y evitando los alimentos irritantes. Para evitar las infecciones es importante, además, utilizar los enjuagues con clorhexidina y nistatina, y administrar aciclovir sistémico para prevenir infecciones por el virus del herpes ${ }^{6,23}$ (TABLA 3).

En la mayoría de los casos, la enfermedad de injerto contra huésped suele ser un diagnóstico de exclusión y deben considerarse otras posibles causas según su clasificación. Los diagnósticos diferenciales de la enfermedad aguda son, principalmente, las reacciones medicamentosas. Estas son difíciles de diferenciar clínicamente, son provocadas principalmente por antibióticos betalactámicos y antifúngicos, su seriedad es variable y pueden evolucionar a una necrólisis epi- 


\begin{tabular}{|c|c|c|c|c|}
\hline & \multicolumn{4}{|c|}{ Hacer tamización anual dermatológica, por el mayor riesgo de presentación de carcinoma escamocelular. } \\
\hline 1. Prevención & \multicolumn{4}{|c|}{$\begin{array}{l}\text { Tres semanas antes de la quimioterapia se deben hacer enjuagues de clorhexidina al o,12 \%, nistatina en solución de } 500.000 \text { U y } \\
\text { yodopovidona tópica, como prevención de la enfermedad oral. }\end{array}$} \\
\hline & \multicolumn{4}{|c|}{ Consulta odontológica, al menos anual, para limpieza y radiografías en caso de sospecha de infección. } \\
\hline & \multicolumn{4}{|c|}{ Si es necesario, se debe brindar asesoría nutricional y vigilancia para infecciones y neoplasia maligna. } \\
\hline \multirow{2}{*}{ 2. Tratamiento tópico } & \multirow{2}{*}{\multicolumn{4}{|c|}{$\begin{array}{l}\text { Se deben evitar comidas ácidas, picantes o condimentadas, que causen molestia y lesiones de la mucosa oral. } \\
\text { El tratamiento tópico brinda mayores beneficios que únicamente el sistémico. }\end{array}$}} \\
\hline & & & & \\
\hline \multirow{10}{*}{$\begin{array}{l}\text { 3. Úlceras y erosiones } \\
\text { - tratamiento tópico }\end{array}$} & \multicolumn{4}{|c|}{ Se recomienda usar esteroides tópicos de gran potencia o inhibidores de la calcineurina. } \\
\hline & \multirow{7}{*}{ En enjuague bucal } & Clobetasol & $0,5 \mathrm{mg} / \mathrm{ml}$ & \multirow{9}{*}{$\begin{array}{l}\text { Aplicar localmente con el dedo, o } \\
\text { con una gasa por } 10 \text { a } 15 \text { minutos }\end{array}$} \\
\hline & & Budesonida & $0,3 \mathrm{mg} / \mathrm{ml}$ & \\
\hline & & Dexametasona & $0,1 \mathrm{mg} / \mathrm{ml}$ & \\
\hline & & Triamcinolona & $1 \mathrm{mg} / \mathrm{ml}$ & \\
\hline & & Tacrolimus & $0,1 \mathrm{mg} / \mathrm{ml}$ & \\
\hline & & Prednisolona & $3 \mathrm{mg} / \mathrm{ml}$ & \\
\hline & & Clobetasol en gel & $0,05 \%$ & \\
\hline & \multirow[t]{2}{*}{ En gel, ungüento o pasta } & Fluocinonida en gel & $0,05 \%$ & \\
\hline & & Tacrolimus en ungüento & $0,10 \%$ & \\
\hline \multirow{5}{*}{ 4. Síntomas de dolor } & $\begin{array}{l}\text { Infiltración } \\
\text { intralesional }\end{array}$ & Triamcinolona & $10 \mathrm{mg} / \mathrm{ml}: 5 \mathrm{ml}$ por $\mathrm{cm}^{2}$ & \\
\hline & \multirow{4}{*}{ Enjuagues bucales } & Lidocaína & $2 \%$ & \\
\hline & & $\begin{array}{l}\text { Lidocaína/benadril en hidróxido de } \\
\text { aluminio o magnesio }\end{array}$ & $\begin{array}{l}\text { Lidocaína al } 2 \% \text { más hid } \\
\text { en jarabe más hidróxido } \\
\text { suspensión }\end{array}$ & $\begin{array}{l}\text { cloruro de difenhidramina } \\
\text { aluminio o de magnesio en }\end{array}$ \\
\hline & & $\begin{array}{l}\text { Diclonina (anestésico local- } \\
\text { antiinflamatorio) }\end{array}$ & $0,5 \%$ sobre todo para do & r muy intenso \\
\hline & & $\begin{array}{l}\text { Caolín pectina-difenhidramina- } \\
\text { lidocaína, 1:1:1 }\end{array}$ & Sin especificación & \\
\hline \multirow{8}{*}{ 5. Boca seca } & Gel, crema de dientes & Flúor & No aplica & \multirow{8}{*}{$\begin{array}{l}\text { Contraindicados en caso de } \\
\text { glaucoma, enfermedad pulmonar } \\
\text { obstructiva crónica o falla } \\
\text { cardiaca }\end{array}$} \\
\hline & Chicle, dulces sin azúcar & Estimulan la producción de saliva & Según necesidad & \\
\hline & \multirow[t]{2}{*}{ Tabletas } & Pilocarpina & $\begin{array}{l}5-10 \mathrm{mg} \text { tres o cuatro } \\
\text { veces al día }\end{array}$ & \\
\hline & & Cevimelina & $15-3 \mathrm{mg}$ tres veces al día & \\
\hline & No aplica & Láser con $\mathrm{CO}_{2}$ & No aplica & \\
\hline & Enjuagues bucales & Agua & Según necesidad & \\
\hline & Otros & $\begin{array}{l}\text { Saliva artificial, lubricantes de la } \\
\text { mucosa oral }\end{array}$ & Según necesidad & \\
\hline & Evitar & $\begin{array}{l}\text { Antidepresivos tricíclicos, inhibidores } \\
\text { de la recaptura de serotonina, } \\
\text { antihistamínicos, opiáceos }\end{array}$ & & \\
\hline \multirow{2}{*}{$\begin{array}{l}\text { 6. Manifestaciones } \\
\text { escleróticas } \\
\text { periorales extensas }\end{array}$} & Fototerapia local & PUVA oral & & \\
\hline & \multicolumn{4}{|c|}{$\begin{array}{l}\text { En estos casos se debe combinar el tratamiento tópico, sobre todo las infiltraciones, acompañado del tratamiento sistémico; también, } \\
\text { se recomiendan terapias fisicas para aumentar la movilidad oral. }\end{array}$} \\
\hline \multirow{3}{*}{ 7. Higiene oral } & \multicolumn{4}{|c|}{ Asegurar una adecuada higiene oral con visitas frecuentes a odontología, cada 3 a 6 meses como mínimo. } \\
\hline & & o molestias, se puede cambiar a una & inos. & \\
\hline & \multicolumn{4}{|c|}{$\begin{array}{l}\text { Si el cepillado y la seda dental no se pueden usar por dolor, usar enjuagues de clorhexidina libres de alcohol; también, se pueden usar } \\
\text { en pacientes con xerostomía quienes tienen con predispoiscion a la caries. }\end{array}$} \\
\hline $\begin{array}{l}\text { 8. Prevención de } \\
\text { infecciones }\end{array}$ & \multicolumn{4}{|c|}{ Usar enjuagues de clorhexidina al 0,12 \%, nistatina en solución de $500.000 U$ y aciclovir sistémico. } \\
\hline
\end{tabular}

*Se recomienda usar un antifúngico (nistatina) cuando se apliquen esteroides orales tópicos.

TABLA 3. Recomendaciones para el manejo del compromiso oral en la enfermedad, aguda o crónica, de injerto contra huésped. 
dérmica tóxica, cuyos hallazgos también podrían confundirse con los de una enfermedad de injerto contra huésped de presentación grave $e^{24-26}$.

Los exantemas virales también pueden similar una enfermedad de injerto contra huésped, sobre todo por el citomegalovirus y el virus del herpes de tipo 6 y 7 , con erupciones máculo-papulares o morbiliformes ${ }^{4,24}$. El síndrome de reconstitución inmunitaria, en el cual hay un retorno de los linfocitos a la circulación periférica después del tratamiento por ablación, puede producir un exantema autolimitado asociado a picos febriles ${ }^{27}$. Otros diagnósticos diferenciales son la dermatitis por radiación y el síndrome del injerto ${ }^{24}$.

Debido a la gran cantidad de manifestaciones que comparte la enfermedad de injerto contra huésped con otras enfermedades, el diagnóstico puede ser desafiante, por lo cual es imperativo practicar la biopsia para confirmarlo, la cual debe ser examinada por patólogos expertos debido a que no hay lesiones patognomónicas en la histopatología ${ }^{24}$. Es de suma importancia una buena correlación clínico-patológica, para llegar al diagnóstico correcto.

El tratamiento debe estar a cargo de un equipo multidisciplinario del cual el dermatólogo hace parte. Está encaminado a disminuir el riesgo de daño de la barrera cutánea, la formación de contracturas y la discapacidad permanente. Depende del grado de compromiso cutáneo, visceral o de mucosas, de las enfermedades concomitantes, de las infecciones y del riesgo de neoplasia maligna.

La piedra angular del tratamiento tópico son los esteroides de mediana a alta potencia. En sitios de alto riesgo de atrofia o cuando se requieren tiempos prolongados, se puede iniciar la aplicacion de inhibi- dores de calcineurina. Los tratamientos sistémicos se utilizan a partir del grado II de compromiso cutáneo, o cuando existan manifestaciones gastrointestinales o hepáticas. La primera línea son los esteroides sistémicos, con los cuales la remisión es completa en 35 a $50 \%$ de los pacientes al día 28 de iniciados ${ }^{28}$. Sin embargo, menos del $50 \%$ de los pacientes tendrán una mejpría duradera después del primer tratamiento y requerirán un segundo tratamiento ${ }^{29}$.

La enfermedad aguda de injerto contra huésped y resistente a los esteroides, tiene una mortalidad de $70 \%$, con escasa respuesta a otros inmunosupresores, por lo cual se hace énfasis en la profilaxis con diferentes esquemas de inmunosupresores, uno o dos días antes del trasplante: ciclosporina más metotrexato o tacrolimus más metotrexato; este último ha demostrado superioridad en la prevención del grado II a IV en la enfermedad aguda ${ }^{30}$.

Entre los tratamientos de segunda línea está la fotoféresis extracorpórea, también llamada fotoquimioterapia extracorpórea, la cual es una terapia inmunomoduladora en la que se toman células mononucleares de la sangre periférica (leucocitos) y se exponen a un agente fotosensible, el psoraleno (8-metoxipsoraleno); posteriormente se tratan con luz ultravioleta A, para ser reinfundidas nuevamente al paciente. Este procedimiento altera las pirimidinas de las bases del ADN y causa apoptosis de las células tratadas $^{31}$. En los últimos años, esta terapia se ha considerado prometedora en aquellos pacientes que no mejoran con los esteroides o en quienes no se ha logrado su suspensión. Produce mejoría completa en 72 $\%$ de los casos y, parciales, en $11 \%$, con supervivencia global a cinco años de $78 \%$, sin mostrar un impacto

\begin{tabular}{|c|c|c|c|}
\hline GRADO & PRIMERA LÍNEA & SEGUNDA LÍNEA & TERCERA LÍNEA \\
\hline Grado I & $\begin{array}{l}\text { Tratamiento tópico } \\
\text { Esteroides de mediana o } \\
\text { gran potencia } \\
\text { Inhibidores de calcineurina } \\
\text { Emolientes } \\
\text { Protección solar }\end{array}$ & ------. & -..--. \\
\hline Grado II- IV & $\begin{array}{l}\text { Prednisona, } 1-2 \mathrm{mg} / \mathrm{kg} / \mathrm{día} \\
\text { por } 7-14 \text { días } \\
\text { Metilprednisolona, } 2 \mathrm{mg} / \mathrm{kg}\end{array}$ & $\begin{array}{l}\text { Micofenolato de mofetilo } \\
\text { Fotoféresis extracorpórea } \\
\text { Anti-TNF } \\
\text { Anti- IL2 }\end{array}$ & $\begin{array}{l}\text { UVB-BE } \\
\text { Pentostatín } \\
\text { Globulina antitimocítica } \\
\text { Ustekinumab } \\
\text { Alemtuzumab (anti-CD52) }\end{array}$ \\
\hline
\end{tabular}

TABLA 4. Tratamiento de la enfermedad aguda de injerto contra huésped. 
negativo sobre la enfermedad de base ${ }^{32,33}$ (TABLA 4).

Como tratamiento de tercera línea se encuentra la terapia biológica, la cual se usa cuando la enfermedad es resistente a los esteroides; no obstante, hacen falta ensayos clínicos multicéntricos, doble ciego y de asignación aleatoria, para obtener una evidencia real. Entre los tratamientos evaluados para la enfermedad aguda de injerto contra huésped, están el alemtuzumab, el ustekinumab y la globulina antitimocítica.

El alemtuzumab se ha usado especialmente en la enfermedad aguda; actúa principalmente contra la glucoproteína $\mathrm{CD}_{52}$, la cual se expresa en linfocitos T, linfocitos B, monocitos, células dendríticas, macrófagos y eosinófilos. En un estudio produjo mejoría en 15 (83 \%) de los casos, de los cuales 6 (33\%) presentaron remisión completa; aún falta información sobre su efecto en la forma crónica de esta enfermedad ${ }^{34}$.

El ustekinumab bloquea la subunidad p40 de la interleucina 12 (IL-12) y de la IL-23, las cuales inhiben la reacción de las células ayudadoras TH1 y TH17; los estudios sobre esta terapia son promisorios, pero, actualmente se encuentran en estudio de fase II $^{35}$.

La globulina antitimocito se administra con base en el conocimiento del papel de los linfocitos $\mathrm{T}$ del donante y su efecto en el surgimiento de la enfermedad de injerto contra huésped, con la cual se obtiene un rango de mejoría parcial de 50 a $56 \%$ y uno de remisión completa de 8 a $36 \%{ }^{36}$.

\section{ENFERMEDAD CRÓNICA DE INJERTO CONTRA HUÉSPED}

La forma crónica de la enfermedad se presenta en 60 a $70 \%$ de los pacientes ${ }^{37}$. Los factores de riesgo incluyen: un alto grado de disparidad HLA; antecedente de una enfermedad aguda de injerto contra huésped; donante femenino y receptor masculino; leucemia mieloide crónica; uso de factor estimulante de colonias de granulocitos; historia de esplenectomía; serología positiva para citomegalovirus en el donante en un receptor seronegativo o reactivación del citomegalovirus en el receptor, y un segundo trasplante alogénico; e historia de enfermedad aguda de injerto contra huésped previa ${ }^{38-40}$.

La piel es el órgano más frecuentemente comprometido en la enfermedad crónica de injerto contra huésped, con reportes hasta del $75 \%$, seguido por la mucosa oral, el hígado, los ojos, el tubo digestivo, el pulmón, el esófago, el aparato genital femenino y las articulaciones ${ }^{41}$.

La mayoría de los casos se diagnostica durante el primer año de trasplante, con una mediana de 4 a 6 meses, pero de 5 a $10 \%$ de los casos se presenta después de un año del trasplante. Casi la mitad de los pacientes tienen compromiso de tres órganos, con necesidad de terapias inmunosupresoras por largo tiempo (mediana de 2 a 3 años), complicaciones secundarias al tratamiento y, por ende, tasas altas de mortalidad pese al tratamiento ${ }^{42}$.

Se considera que esta enfermedad representa un síndrome, en el cual intervienen diferentes factores, como son un estado inflamatorio crónico, pérdida de la regulación de la inmunidad celular innata-adaptativa y la inmunidad humoral producida por una producción aberrante del factor de crecimiento transformador $\beta$ (TGF- $\beta$ ), producción de autoanticuerpos y deficiencia en el número y en la función de las células $\mathrm{T}$ reguladoras (Treg) ${ }^{43}$.

Las manifestaciones cutáneas de la enfermedad crónica de injerto contra huésped son polimorfas, y se han dividido en patognomónicas (de tipo liquenoide o esclerótico) y presuntivas (que requieren de confirmación histopatológica). El diagnóstico requiere, al menos, de un signo diagnóstico patognomónico o de un signo presuntivo confirmado por histopatología (TABLA 5).

Las manifestaciones cutáneas patognomónicas de tipo liquenoide consisten en pápulas o placas eritemato-violáceas descamativas, confluentes, localizadas en la región periorbitaria, los pabellones auriculares,

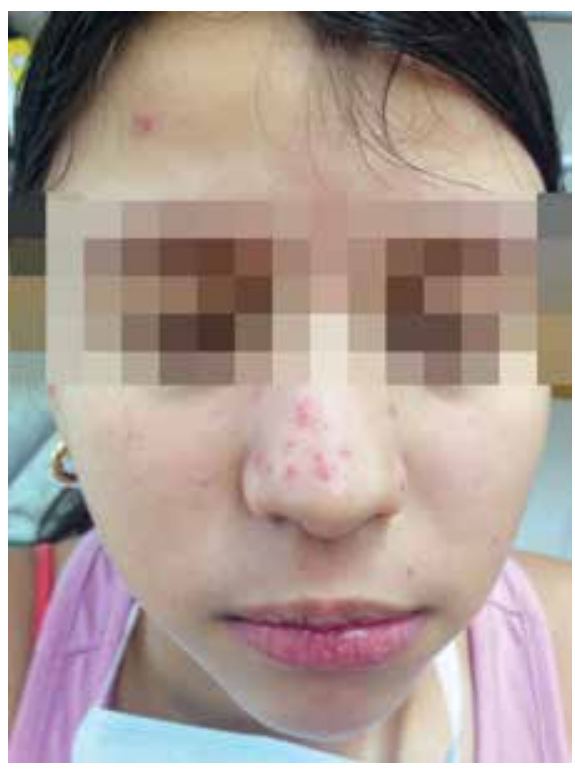

FIGURA 6. Enfermedad crónica de injerto contra huésped de tipo liquenoide: pápulas eritemato-violáceas en la cara 


\begin{tabular}{|c|c|c|c|}
\hline Sitio afectado & $\begin{array}{l}\text { Manifestaciones } \\
\text { patognomónicas }\end{array}$ & Manifestaciones presuntivas & $\begin{array}{c}\text { Manifestaciones comunes a la } \\
\text { forma aguda y a la crónica }\end{array}$ \\
\hline Piel & $\begin{array}{c}\text { Poiquilodermia } \\
\text { Similar al liquen plano } \\
\text { Esclerosis } \\
\text { Similar a morfea } \\
\text { Similiar a liquen escleroso }\end{array}$ & $\begin{array}{c}\text { Cambios en la pigmentación } \\
\text { Queratosis pilaris }\end{array}$ & $\begin{array}{c}\text { Erupción maculopapular } \\
\text { Prurito }\end{array}$ \\
\hline Uñas & --- & $\begin{array}{l}\text { Distrofia } \\
\text { Onicólisis } \\
\text { Pérdida ungular } \\
\text { Pterigio ungular }\end{array}$ & $\cdots$ \\
\hline Cuero cabelludo & --- & $\begin{array}{c}\text { Alopecia cicatricial o no cicatricial } \\
\text { Descamación }\end{array}$ & $--\cdot$ \\
\hline Oral & Similar al liquen plano & $\begin{array}{l}\text { Xerostomía } \\
\text { Mucocele } \\
\text { Atrofia mucosa } \\
\text { Úlceras }\end{array}$ & $\begin{array}{l}\text { Gingivitis } \\
\text { Mucositis } \\
\text { Eritema } \\
\text { Dolor }\end{array}$ \\
\hline Genitales & $\begin{array}{l}\text { Similar al liquen plano } \\
\text { Similar al liquen escleroso } \\
\text { Estenosis o cicatrices, } \\
\text { vaginales o uretrales }\end{array}$ & $\begin{array}{l}\text { Erosiones } \\
\text { Fisuras } \\
\text { Úlceras }\end{array}$ & $---\cdot$ \\
\hline
\end{tabular}

TABLA 5. Manifestaciones clínicas de la enfermedad crónica de injerto contra huésped.

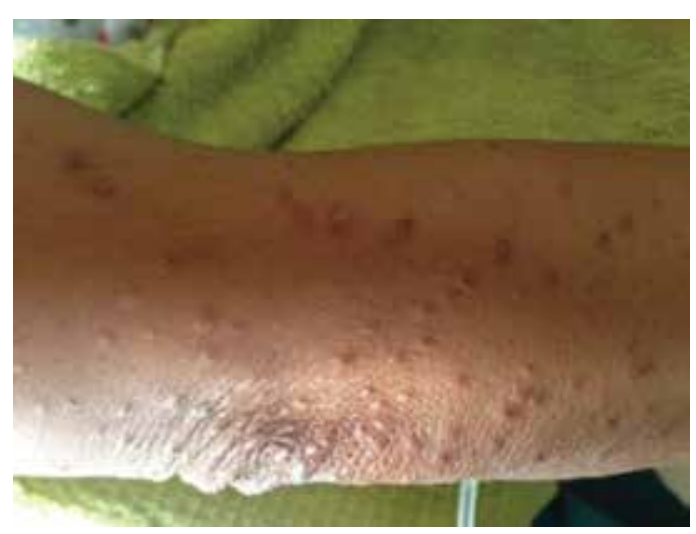

FIGURA 7. Enfermedad crónica de injerto contra huésped: pápulas eritemato-violáceas en miembros superiores

las palmas y las plantas (FIGURAS 6 Y 7). Estas lesiones son similares a las del liquen plano, el liquen escleroso y la morfea, y su aparición hace el diagnóstico de enfermedad de injerto contra huésped crónica; sin embargo, el examen clínico no es suficiente para hacer el diagnóstico y es de mucha importancia practicar una biopsia para su confirmación ${ }^{30}$.

Las manifestaciones cutáneas patognomónicas de tipo esclerótico se presentan en 3,5 \% de los receptores de trasplantes alogénicos ${ }^{23}$. Pueden ser prece- didas por pigmentación periocular, lo cual predice una enfermedad extensa. Las lesiones consisten en placas induradas, esclerosas, blanco-amarillentas y mal delimitadas, o poiquilodermia que se inicia en el tórax y los hombros. Las lesiones suelen progresar y generalizarse, asociándose a la aparición de contracturas y disminución de la apertura oral.

Se han descrito otras manifestaciones crónicas, que son características pero no hacen el diagnóstico, como son: cambios en la pigmentación: alteraciones ungulares de tipo distrofia; onicólisis; eritema periungular; lesiones similares al eritema multiforme; dermatomiositis; lupus eritematoso sistémico; lesiones psoriasiformes; lesiones similares a la queratosis pilaris e, incluso, lesiones parecidas a las de la dermatitis atópica, lo cual convierte el diagnóstico en un reto ${ }^{44,45}$.

En cuanto al diagnóstico diferencial de la enfermedad crónica de injerto contra huésped, incluye el liquen plano, las enfermedades escleróticas que, a diferencia de lo que sucede en enfermedad crónica de injerto contra huésped, se inician con progresión distal, y finalmente, la poiquilodermia, la cual generalmente se presenta en el cuello y se asocia con otras enfermedades, especialmente las reumatológicas ${ }^{20}$.

Las manifestaciones orales se presentan en 45 a 83 $\%$ de los casos, como lesiones en la mucosa, frecuentemente similares al liquen plano oral, con compromiso de las glándulas salivares por hipofunción y xerostomía, 
y compromiso esclerótico de la mucosa oral y de los tejidos blandos adyacentes, que produce disminución de la apertura oral ${ }^{23,46}$. La sintomatología es diversa e incluye dolor, sensibilidad a varios alimentos y bebidas, alteración del gusto y caries dental.

Las lesiones en la mucosa oral son de gravedad variable, e incluyen eritema asociado o no a edema, atrofia o ambas, úlceras y mucoceles. Las lesiones liquenoides similares al liquen plano, pueden asociarse a leucoplaquias hiperqueratósicas, las cuales son diagnósticas de enfermedad crónica de injerto contra huésped.

Las úlceras son muy dolorosas y pueden acompañarse de seudomembranas, que son la ruta más fácil para adquirir infecciones en estos pacientes. Los mucoceles, usualmente asintomáticos, se localizan en el paladar y en los labios, y consisten en lesiones en forma de cúpula, llenas de líquido claro, rodeados por mucosa normal. Se producen por fibrosis y oclusión del conducto salivar, secundarias a la disfunción de las glándulas salivales que presentan estos pacientes, la cual se manifiesta por disminución del flujo salival y xerostomía hasta en $77 \%$ de los casos, a menudo asociadas a ojo seco y síntomas similares a los del síndrome de Sjögren.

En la cavidad oral, el diagnóstico de enfermedad crónica de injerto contra huésped requiere que se excluyan otras causas como las infecciones, como herpes simple o candidiasis oral; por lo anterior, ante la sospecha de infección, siempre se debe tomar una biopsia de la mucosa oral y hacer el cultivo. También, se deben descartar las reacciones medicamentosas y las lesiones neoplásicas recurrentes o de novo, por lo cual se recomienda la biopsia para confirmar el diagnóstico, interpretada por un patólogo experto.

El tratamiento se enfoca en prevenir la infección mediante una adecuada higiene oral con enjuagues con clorhexidina, en disminuir el dolor, y en tratar las lesiones de las mucosas y los síntomas que afectan la calidad de vida, como la xerostomía. Además, se deben hacer evaluaciones periódicas cada seis meses, por el mayor riesgo de carcinoma escamocelular oral $^{46,47}$ (TABLA 3).

Los hallazgos histológicos iniciales de la enfermedad crónica de injerto contra huésped, se caracterizan por un denso infiltrado inflamatorio mononuclear, con acantosis irregular, hiperqueratosis o atrofia. Dependiendo de las manifestaciones clínicas, se pueden encontrar dos tipos de patrones histológicos:

- Patrón liquenoide: acantosis, hipergranulosis, hiperqueratosis, crestas papilares en forma de punta e infiltrado inflamatorio leve en la dermis superior.
- $\quad$ Patrón esclerodermiforme: hiperqueratosis leve y compacta, atrofia epidérmica, taponamiento folicular, fibrosis del colágeno y pérdida de grasa perianexial.

Para el diagnóstico existen tres categorías ${ }^{18}$ :

- Diagnóstico negativo: sin evidencia de enfermedad de injerto contra huésped.

- Posible enfermedad de injerto contra huésped: manifestaciones clínicas e histopatológicas no patognomónicas de esta enfermedad y razones para sospechar otros diagnósticos, como reacciones medicamentosas.

- Probable enfermedad de injerto contra huésped: manifestaciones clínicas patognomónicas de la enfermedad, sin otra causa que las explique, o una biopsia confirmatoria.

El tratamiento debe estar a cargo de un equipo multidisciplinario; constituye un reto y su elección depende del sitio afectado, de la gravedad de los síntomas y del esquema profiláctico usado. Está encaminado a disminuir los síntomas y controlar la actividad de la enfermedad, sin causar una toxicidad desproporcionada (TABLA 5). A largo plazo, el objetivo es desarrollar tolerancia inmunológica, con una adecuada suspensión del tratamiento inmunosupresor.

Los pacientes con compromiso cutáneo leve pueden mejorar con tratamientos dirigidos a la piel, con un control periódico y evaluación de los síntomas producidos por otros órganos. Los emolientes son necesarios en casos de xerosis, y manifestaciones liquenoides y esclerodermoides, así como los esteroides tópicos, los inhibidores de la calcineurina o ambos, los cuales se recomiendan como la primera línea de tratamiento ${ }^{48}$.

En casos de compromiso moderado a grave, los esteroides sistémicos son la piedra angular del tratamiento, a dosis de 0,5 a $1 \mathrm{mg} / \mathrm{kg} /$ día, con disminución progresiva de los esteroides una vez se haya logrado la remisión completa o una muy buena mejoría parcial. Si hay persistencia o recurrencia de la enfermedad con la disminución progresiva de los esteroides, estos se deben continuar por tres meses como mínimo, hasta intentar de nuevo su disminución, la cual se debe llevar hasta una dosis de $0,1 \mathrm{mg} / \mathrm{kg} /$ día; esta puede suspenderse después de cuatro semanas, si no hay signos de reaparición de la enfermedad ${ }^{49}$.

Los tratamientos combinados con un ahorrador de esteroides, no han demostrado diferencias estadísticamente significativas en la supervivencia o la duración del tratamiento, aunque se requiere de ensayos clínicos controlados que sustenten su uso.

La fototerapia puede contribuir a la mejoría de estos 
1. Evaluación por un equipo multidisciplinario que incluya a un dermatólogo con experiencia en este campo

2. Pacientes con la forma crónica en inmunosupresión prolongada, deben visitar, como mínimo, una vez al año al dermatólogo, por el mayor riesgo de neoplasias malignas cutáneas.

3. Emolientes para el control de los síntomas

4. Manejo del prurito con antihistamínicos orales; si no hay mejoría, 25-50 $\mathrm{mg}$ de doxepina en la noche o gabapentín.

5. Protección solar

6. Tratamiento tópico que incluya esteroides o inhibidores de la calcineurina como primera línea de tratamiento.

7. Fisioterapia en pacientes con enfermedad esclerodermoide

8. Manejo de las úlceras en las extremidades; considerar vendajes multicapa, medias de gradiente y valoración por cirugía vascular

9. Evaluar la distrofia ungular. Masaje con esteroides de gran potencia o inhibidores tópicos de calcineurina

10. Evaluar la alopecia: en fases tempranas puede ser reversible. Garantizar niveles adecuados de hierro, ferritina, vitamina B12, cinc y vitamina D.

11. Evaluar el aparato genital y la mucosa oral

TABLA 5. Recomendaciones para el manejo de la enfermedad crónica de injerto contra huésped.

pacientes. La UVB-BE (311 $\mathrm{nm}$ ) se utiliza en el tratamiento de la enfermedad liquenoide, mientras que la PUVA (320-400 nm) y la UVA-1 (340-400 nm) se utilizan en casos de enfermedad esclerodermoide ${ }^{48,50}$.

Hasta en 60 a $70 \%$ de los casos hay fallas en el tratamiento primario, por lo cual se debe recurrir a los de segunda línea, especialmente, en caso de empeoramiento de las manifestaciones clínicas existentes, aparición de nuevos síntomas y signos en órganos que no habían sido afectados, ausencia de mejoría después de un mes de tratamiento, imposibilidad para disminuir los esteroides después de dos meses a dosis de $1 \mathrm{mg} / \mathrm{kg} /$ día o signos de toxicidad. Sin embargo, no hay consenso o guías al respecto $\mathrm{y}$, en muchas ocasiones, los tratamientos se basan en la experiencia de los médicos tratantes, en el riesgo de toxicidad y en la potencial exacerbación de enfermedades concomitantes preexistentes.

La fotoféresis extracorpórea ha demostrado remisión completa hasta en $80 \%$ de los pacientes, especialmente, en casos de compromiso esclerodermoide, con tiempos de duración de 12 semanas $^{31,50,51,53}$ (TABLA 3).

Existen otros tratamientos reportados, como la talidomida y los agentes biológicos. La talidomida es un agente inmunomodulador y antiangiogénico, usado en algunas series de casos para el tratamiento de la enfermedad crónica de injerto contra huésped resistente al tratamiento con corticoesteroides. Sin embargo, sus efectos beneficiosos siguen siendo difíciles de evaluar y se debe tener en cuenta que tiene múltiples efectos adversos, los cuales son frecuentes y pueden llegar a obligar a suspenderla, como sedación, estreñimiento, exantema y neuropatía, entre otros ${ }^{54}$.

La terapia biológica, al igual que en la forma aguda de la enfermedad, requiere múltiples estudios adicionales. Entre los medicamentos más investigados están el rituximab y el mesilato de imatinib.

El rituximab es uno de los medicamentos hasta ahora más estudiados, sobretodo en la forma crónica de la enfermedad, con una tasa relativa de éxito debido a que disminuye los linfocitos $\mathrm{B}$, los cuales están implicados en la fisiopatología de la enfermedad al producir anticuerpos contra el $\mathrm{HLA}^{55}$. Con este medicamento se ha observado una tasa de éxito de 43 a $83 \%$, con reducción de las dosis de corticoesteroides y de las manifestaciones clínicas; igualmente, se logró suspender los esteroides hasta en $10 \%$ de los casos; no obstante, se puede llegar a necesitar profilaxis para infecciones ${ }^{55}$.

El mesilato de imatinib inhibe la tirosina cinasa, la cual participa en múltiples vías de señalización implicadas en la fibrosis cutánea. Actualmente, hay prometedores estudios de fase II que muestran mejoría parcial de $36 \%$, estabilidad de la enfermedad de $50 \%$ y progreso de la misma en $14 \%$, e igualmente, mejoría de la movilidad en un rango de 3 a $94 \%$. Por esto, el imatinib se recomienda como uno de los múltiples tratamientos, principalmente en la enfermedad crónica de tipo escleroso, a dosis bajas para mejorar el rango de movilidad ${ }^{56}$.

\section{CONCLUSIONES}

Los trasplantes hematopoyéticos son una alternativa terapéutica cada vez más utilizada y han logrado la recuperación de pacientes con neoplasias hematológicas que de otra forma fallecerían rápidamente. Este tratamiento no está exento de riesgos y la enfermedad de injerto contra huésped es su principal complicación inmunológica. En sus formas agudas, esta enfermedad puede llevar a la muerte del paciente por necrólisis epidérmica tóxica y, en sus formas crónicas, las manifestaciones esclerodermiformes graves deterioran la calidad de vida con lesiones similares a las de la esclerosis sistémica. 
El dermatólogo debe estar atento a contribuir en el diagnóstico apropiado de los pacientes, estableciendo el diagnóstico diferencial de la enfermedad aguda de injerto contra huésped frente a la infección por citomegalovirus y las toxicodermias, y ayudando al cuidado de la piel y las mucosas, y en las formas crónicas, colaborando con el equipo multidisciplinario.

\section{REFERENCIAS}

1. Pasquini M, Wang Z, Horowitz MM, Gale RP. 2013 report from the Center for International Blood and Marrow Transplant Research (CIBMTR): Current uses and outcomes of hematopoietic cell transplants for blood and bone marrow disorders. Clin Transpl. 2013;187-97.

2. Enfermedad injerto contra huésped en el trasplante hematopoyético. Piel. 2004;19:431-41. Fecha de consulta: 16 de febrero de 2015. Disponible en: http://www.carmenbrufau.es/ images/EICH.pdf.

3. Hymes SR, Alousi AM, Cowen EW. Graft-versus-host disease: part I. Pathogenesis and clinical manifestations of graftversus-host disease. J Am Acad Dermatol. 2012;66:515.e1-18.

4. Peñas PF, Zaman S. Many faces of graft-versus-host disease. Australas J Dermatol. 2010;51:1-10.

5. Billingham RE. The biology of graft-versus-host reactions. Harvey Lect. 1966-1967;62:21-78.

6. Jagasia M, Giglia J, Chinratanalab W, Dixon S, Chen H, Frangoul $\mathrm{H}$, et al. Incidence and outcome of chronic graft-versushost disease using National Institutes of Health consensus criteria. Biol Blood Marrow Transplant. 2007;13:1207-15. Fecha de consulta: 16 de febrero de 2015. http://www.bbmt. org/article/S1083-8791(07)00338-2/pdf.

7. Flowers MED, Inamoto Y, Carpenter PA, Lee SJ, Kiem H-P, Petersdorf EW, et al. Comparative analysis of risk factors for acute graft-versus-host disease and for chronic graft-versushost disease according to National Institutes of Health consensus criteria. Blood. 2011;117:3214-9. Fecha de consulta: 16 de febrero de 2015. Disponible en: http://www.ncbi.nlm.nih. gov/pmc/articles/PMC3062319/.

8. Vigorito AC, Campregher P V, Storer BE, Carpenter PA, Moravec CK, Kiem H-P, et al. Evaluation of NIH consensus criteria for classification of late acute and chronic GVHD. Blood. 2009;114:702-8. Fecha de consulta: 16 de febrero de 2015. Disponible en: http://www.ncbi.nlm.nih.gov/pmc/articles/PMC2713471/.

9. Filipovich AH, Weisdorf D, Pavletic S, Socie G, Wingard JR, Lee SJ, et al. National Institutes of Health consensus development project on criteria for clinical trials in chronic graftversus-host disease: I. Diagnosis and staging working group report. Biol Blood Marrow Transplant. 2005;11:945-55. Fecha de consulta: 19 de septiembre de 2014. Disponible en: http:// www.bbmt.org/article/S1083-8791(05)00631-2/pdf.

10. Velásquez M. Enfermedad injerto contra huésped. Rev Asoc Colomb Alerg Asma Inmunol. 2001;10:110-9.

11. Jacobsohn DA, Vogelsang GB. Acute graft versus host disease. Orphanet J Rare Dis. 2007;2-35. Fecha de consulta: 7 de enero de 2015. Disponible en: http://www.ncbi.nlm.nih.gov/pmc/ articles/PMC2018687/.
12. Szydlo R, Goldman JM, Klein JP, Gale RP, Ash RC, Bach FH, et al. Results of allogeneic bone marrow transplants for leukemia using donors other than HLA-identical siblings. J Clin Oncol. 1997;15:1767-77. Fecha de consulta: 16 de febrero de 2015. Disponible en: http://web.b.ebscohost.com.bdigital. ces.edu.co:2048/ehost/pdfviewer/pdfviewer?sid=c665a1f8c249-4db5-bcc7-b84bacdc5822\%40sessionmgr107\&vid=1 \&hid $=124$.

13. Beatty PG, Clift RA, Mickelson EM, Nisperos BB, Flournoy N, Martin PJ, et al. Marrow transplantation from related donors other than HLA-identical siblings. N Eng J Med. 1985:313:765-71.

14. Murashige N, Kami M, Mori SI, Katayama Y, Kobayashi K, Onishi Y, et al. Characterization of acute graft-versus-host disease following reduced-intensity stem-cell transplantation from an HLA-identical related donor. Am J Hematol. 2008;83:630-4.

15. Flomenberg N, Baxter-Lowe LA, Confer D, Fernández-Vina M, Filipovich A, Horowitz M, et al. Impact of HLA class I and class II high-resolution matching on outcomes of unrelated donor bone marrow transplantation: HLA-C mismatching is associated with a strong adverse effect on transplantation outcome. Blood. 2004;104:1923-30. Fecha de consulta: 16 de febrero de 2015. Disponible en: http://www.bloodjournal.org/ content/104/7/1923.long?sso-checked=true.

16. Petersdorf EW, Kollman C, Hurley CK, Dupont B, Nademanee A, Begovich AB, et al. Effect of HLA class II gene disparity on clinical outcome in unrelated donor hematopoietic cell transplantation for chronic myeloid leukemia: The US National Marrow Donor Program Experience. Blood. 2001;98:2922-9. Fecha de consulta: 20 de febrero de 2015. Disponible en: http://www.bloodjournal.org/content/98/10/2922.long.

17. Przepiorka D, Weisdorf D, Martin P, Klingemann HG, Beatty P, Hows J, et al. 1994 Consensus Conference on Acute GVHD Grading. Bone Marrow Transplant. 1995;15:825-8.

18. Shulman HM, Cardona DM, Greenson JK, Hingorani S, Horn T, Huber E, et al. NIH Consensus development project on criteria for clinical trials in chronic graft-versus-host disease: II. The 2014 Pathology Working Group Report. Biol Blood Marrow Transplant. 2015;21:589-603. Fecha de consulta: 22 de julio de 2015. Disponible en: http://www-ncbi-nlm-nih-gov.bdigital. ces.edu.co:2048/pmc/articles/PMC4359636/.

19. Imanguli $M$, Alevizos I, Brown R, Pavletic $S$, Atkinson J. Oral graft-versus-host disease. Oral Dis. 2008;14:396-412. Fecha de consulta: 3 de marzo de 2015. Disponible en: http://www. ncbi.nlm.nih.gov/pmc/articles/PMC2565862/.

20. Vargas-Díez E, García-Díez A, Marín A, Fernández-Herrera J. Life-threatening graft-vs-host disease. Clin Dermatol. 2005;23:285-300.

21. Levy-Polack MP, Sebelli P, Polack NL. Incidence of oral complications and application of a preventive protocol in children with acute leukemia. Spec Care Dentist.1998;18:189-93.

22. Reyes AD, Martín TA, Leache EB, Suárez C. Manifestaciones orales en la enfermedad injerto contra huésped (EICH). Presentación de un caso. Med Oral. 2003;8: 361-5. Fecha de consulta: 5 de febrero de 2016. Disponible en: http://www. medicinaoral.com/pubmed/medoralv8_i5_p361.pdf.

23. Mays JW, Fassil H, Edwards DA, Pavletic SZ, Bassim CW. Oral chronic graft-versus-host disease: Current pathogenesis, therapy, and research. Oral Dis. 2013;19:327-46. Fecha de consulta: 5 de febrero de 2016. Disponible en: http://www.ncbi. nlm.nih.gov/pmc/articles/PMC3561479/?tool=pmcentrez. 
24. Mays SR, Kunishige JH, Truong E, Kontoyiannis DP, Hymes SR. Approach to the morbilliform eruption in the hematopoietic transplant patient. Semin Cutan Med Surg. 2007;26:155-62.

25. Lützow-Holm C, Rønnevig JR. Cutaneous drug reactions. Tidsskr Nor Laegeforen. 2005;125:2483-7.

26. Byun HJ, Yang JI, Kim BK, Cho KH. Clinical differentiation of acute cutaneous graft-versus-host disease from drug hypersensitivity reactions. J Am Acad Dermatol. 2011;65:726-32.

27. Horn TD, Redd J V, Karp JE, Beschorner WE, Burke PJ, Hood AF. Cutaneous eruptions of lymphocyte recovery. Arch Dermatol. 1989;125:1512-7.

28. Martín PJ, Rizzo JD, Wingard JR, Ballen K, Curtin PT, Cutler $\mathrm{C}$, et al. First- and second-line systemic treatment of acute graft-versus-host disease: Recommendations of the American Society of Blood and Marrow Transplantation. Biol Blood Marrow Transplant. 2012;18:1150-63. Fecha de consulta: 10 de marzo de 2015. Disponible en: http://www.ncbi.nlm.nih.gov/ pmc/articles/PMC3404151/.

29. Hymes SR, Alousi AM, Cowen EW. Graft-versus-host disease: part II. Management of cutaneous graft-versus-host disease. J Am Acad Dermatol. 2012;66:535.e1-16.

30. Ratanatharathorn V, Nash RA, Przepiorka D, Devine SM, Klein JL, Weisdorf D, et al. Phase III study comparing methotrexate and tacrolimus (prograf, FK506) with methotrexate and cyclosporine for graft-versus-host disease prophylaxis after HLA-identical sibling bone marrow transplantation. Blood. 1998;92:2303-14. Fecha de consulta: 10 de marzo de 2015. Disponible en: http://www.bloodjournal.org/content/92/7/2303. long?sso-checked=true.

31. Klassen J. The role of photopheresis in the treatment of graftversus-host disease. Curr Oncol. 2010;17:55-8.

32. Calore E, Marson P, Pillon M, Tumino M, Tison T, Mainardi C, et al. Treatment of acute GVHD in childhood with extracorporeal photochemotherapy/phofotopheresis: The Padova experience. Biol Blood Marrow Transplant. 2015;21:1963-72.

33. Greinix HT, Worel N, Just U, Knobler R. Extracorporeal photopheresis in acute and chronic graft-versus-host disease. Transfus Apher Sci. 2014:50:349-57. Fecha de consulta: 25 de julio de 2015. Disponible en: https://www-clinicalkeycom.bdigital.ces.edu.co:2443/service/content/pdf/ watermarked/1-s2.o-S1473050214000810.pdf?locale=en_US.

34. Gómez-Almaguer D, Ruiz-Argüelles GJ, del Carmen TarínArzaga L, González-Llano O, Gutiérrez-Aguirre H, Cantú Rodríguez 0, et al. Alemtuzumab for the treatment of steroidrefractory acute graft-versus-host disease. Biol Blood Marrow Transplant. 2008;14:10-5.

35. Teshima T, Maeda Y, Ozaki K. Regulatory T cells and IL-17-producing cells in graft-versus-host disease. Immunotherapy. 2011;3:833-52.

36. Pidala J, Anasetti C. Glucocorticoid-refractory acute graft-versus-host disease. Biol Blood Marrow Transplant. 2010;16:1504-18. Disponible en: http://www.bbmt.org/article/ S1083-8791(10)ooo12-1/pdf.

37. Lee SJ, Vogelsang G, Flowers MED. Chronic graft-versus-host disease. Biol Blood Marrow Transplant. 2003;9:215-33.

38. Horwitz ME, Sullivan KM. Chronic graft-versus-host disease. Blood Reviews. 2006;20:15-27.

39. Wojnar J, Giebel S, Holowiecka-Goral A, Krawczyk-Kulis M, Markiewicz M, Wozniczka K, et al. The incidence and risk factors for chronic graft-versus-host-disease. Ann Transplant. 2006;11:14-20.
40. Storb R, Prentice RL, Sullivan KM, Shulman HM, Deeg HJ, Doney KC, et al. Predictive factors in chronic graft-versus-host disease in patients with aplastic anemia treated by marrow transplantation from HLA-identical siblings. Ann Intern Med. 1983;98:461-6. Fecha de consulta: 22 de febrero de 2015. Disponible en: http://web.a.ebscohost.com.bdigital.ces.edu. co:2048/ehost/pdfviewer/pdfviewer?sid=128e226f-821d-41559510-6734dbdad12b\%40sessionmgr4004\&vid=1\&hid=4209.

41. Lee SJ, Flowers MED. Recognizing and managing chronic graft-versus-host disease. Hematology Am Soc Hematol Educ Program. 2008:134-41. Fecha de consulta: 22 de febrero de 2015. Disponible en: http://asheducationbook.hematologylibrary.org/content/2008/1/134.long.

42. Lee SJ, Klein JP, Barrett AJ, Ringden O, Antin JH, Cahn J-Y, et al. Severity of chronic graft-versus-host disease: Association with treatment-related mortality and relapse. Blood. 2002;100:406-14. Fecha de consulta: 15 de julio de 2015. Disponible en: http://www.bloodjournal.org/content/100/2/406. long?sso-checked=true.

43. Martin PJ. Biology of chronic graft-versus-host disease: Implications for a future therapeutic approach. Keio J Med. 2008;57:177-83.

44. Wei J, Zhang Y, Xu H, Jin J, Zhang J. Atopic dermatitis-like presentation of graft-versus-host disease: A novel form of chronic cutaneous graft-versus-host disease. J Am Acad Dermatol. 2013;69:34-9.

45. Cornejo CM, Kim EJ, Rosenbach M, Micheletti RG. Atypical manifestations of graft-versus-host disease. J Am Acad Dermatol. 2015;72:690-5.

46. Carpenter PA, Kitko CL, Elad S, Flowers MED, Gea-Banacloche JC, Halter JP, et al. National Institutes of Health Consensus Development Project on Criteria for Clinical Trials in Chronic Graft-versus-Host Disease: V. The 2014 Ancillary Therapy and Supportive Care Working Group Report. Biol Blood Marrow Transplant. 2015;21:1167-87. Fecha de consulta: 5 de febrero de 2016. Disponible en: http://www.sciencedirect.com/science/ article/pii/S1083879115002244

47. Hashemi A, Bahrololoumi Z, Khaksar Y, Saffarzadeh N, Neamatzade H, Foroughi E. Mouth-rinses for the prevention of chemotherapy induced oral mucositis in children: A systematic review. Iran J Pediatr Hematol Oncol. 2015;5:106-12. Fecha de consulta: 20 de febrero de 2016. Disponible en: http://www-ncbi-nlm-nih-gov.bdigital.ces.edu.co:2048/pmc/ articles/PMC4475632/.

48. Dignan FL, Scarisbrick JJ, Cornish J, Clark A, Amrolia P, Jackson $\mathrm{G}$, et al. Organ-specific management and supportive care in chronic graft-versus-host disease. Br J Haematol. 2012;158:6278. Fecha de consulta: 22 de marzo de 2015. Disponible en: http://web.b.ebscohost.com.bdigital.ces.edu.co:2048/ehost/ pdfviewer/pdfviewer?sid=d82f56oa-1ec3-4ab5-84d1-e685595 bd253\%40sessionmgr104\&vid=1\&hid $=124$.

49. Flowers MED, Martin PJ. How we treat chronic graft-versushost disease. Blood. 2015;125:606-15. Fecha de consulta: 29 de junio de 2015. Disponible en: http://www.ncbi.nlm.nih.gov/ pmc/articles/PMC4304105/.

50. Ballester-Sánchez R, Navarro-Mira MÁ, de Unamuno-Bustos B, Pujol-Marco C, Sanz-Caballer J, Botella-Estrada R. The role of phototherapy in cutaneous chronic graft-vs-host disease: A retrospective study and review of the literature. Actas Dermosifiliogr. 2015;106:651-7. Fecha de consulta: 24 de julio de 2015. Disponible en: http://www.actasdermo.org/en/the-rolephototherapy-in-cutaneous/articulo/S1578219015002188/. 
51. Ratcliffe N, Dunbar NM, Adamski J, Couriel D, Edelson $\mathrm{R}$, Kitko CL, et al. National Institutes of Health State of the Science Symposium in Therapeutic Apheresis: Scientific opportunities in extracorporeal photopheresis. Transfus Med Rev. 2015;29:62-70.

52. Zhu L, Couriel DR, Chang C-H. The effect of extracorporeal photopheresis on T cell response in chronic graft-versus-host disease. Leuk Lymphoma. 2015;18:1-9.

53. Velásquez MM. Inmunointervención: fotoféresis, radioféresis, vacunas con células dendríticas. Rev Asoc Colomb Alerg Asma Inmunol. 2001;10:77-84.

54. Peñas PF, Fernández-Herrera J, García-Diez A. Dermatologic treatment of cutaneous graft versus host disease. Am J Clin Dermatol. 2004;5:403-16.

55. Kim SJ, Lee JW, Jung CW, Min CK, Cho B, Shin HJ, et al. Weekly rituximab followed by monthly rituximab treatment for steroid-refractory chronic graft-versus-host disease: Results from a prospective, multicenter, phase II study. Haematologica. 2010;95:1935-42.

56. Baird K, Comis LE, Joe GO, Steinberg SM, Hakim FT, Rose JJ, et al. Imatinib mesylate for the treatment of steroid-refractory sclerotic-type cutaneous chronic graft-versus-host disease. Biol Blood Marrow Transplant. 2015;21(6):1083-90. 